\title{
Human milk fatty acids and growth of infants in Brazzaville (The Congo) and Ouagadougou (Burkina Faso)
}

\author{
G Rocquelin ${ }^{1, *}$, S Tapsoba ${ }^{2}$, J Kiffer ${ }^{1}$ and S Eymard-Duvernay ${ }^{1}$ \\ 'IRD, UR 106 'Nutrition, Alimentation, Sociétés', BP 64501, F-34394 Montpellier Cedex 5, France: \\ ${ }^{2}$ Direction Régionale de la Santé du itouet, Centre Régional de Nutrition, Bobo-Dioulasso, Burkina Faso
}

Submitted 25 March 2002: Accepted 5 September 2002

\begin{abstract}
Objective: To estimate the role of human milk $n-6$ and $n-3$ polyunsaturated fatty acids (PUFA) in term infant growth in two African urban populations.

Design: Observational study. Weight gains at 5 months of age and dietary habits were compared between Congolese infants $(n=102)$ and Burkinabè infants $(n=101)$. Socio-economic status and anthropometry of the mothers were also recorded.

Setting: One suburban district in Brazzaville (capital of The Congo) and one in Ouagadougou (capital of Burkina Faso).

Subjects: Two random samples of nursing mothers and their 5-month-old infants.

Results: All infants were born at term and there was no difference in birth weights. At 5 months of age, infants in Ouagadougou were thinner but not shorter than their counterparts in Brazzaville (average weight gain (standard deviation): 614 (168) $\mathrm{g}$ month ${ }^{-1}$ vs. $\left.720(176) \mathrm{g}_{\text {month }}^{-1} ; P<0.0001\right)$. Drastic differences were found in infant diets with regard to extra fluid intake and $n-6$ and $n-3$ PUFA concentrations in breast milk. In Ouagadougou, all infants were given fluids other than milk from birth. Breast milk had highly unbalanced 18:2n-6/18:3n -3 and $n-6 / n-3$ long-chain PUFA ratios (53:1 and 5:1, respectively). In Brazzaville, half of the infants received fluids other than milk, and breast milk showed balanced 18:2n-6/18:3n-3 and $n-6 / n-3$ long-chain PUFA ratios (12:1 and 1:1, respectively). A non-linear relationship between $18: 2 n-6 / 18: 3 n-3$ ratio and growth was established in Brazzaville $(P=0.0027)$. The 18:2n-6/18:3n-3 ratio adjusted with covariates had an even more significant effect on weight gain $(P=0.0011)$. Applying the same model in Ouagadougou did not show such a relation. Conclusion: Data strongly suggest that a balanced ratio of $18: 2 n-6 / 18: 3 n-3$ (between 5:1 and 15:1) in breast milk leads to higher weight gain of infants during the first 5 months of life.
\end{abstract}

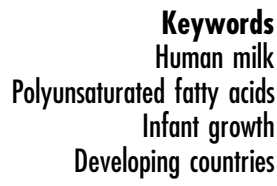

The implication of dietary essential fatty acids (EFA) and/or their associated long-chain (LC) polyunsaturated fatty acids (PUFA) in promoting growth in pre-term and term infants has recently been reviewed extensively ${ }^{1,2}$. Most of the reviewed studies on term infants showed that, during their first 12 months of life, infants fed formulas supplemented with LC $n-6$ and/or LC $n-3$ PUFA had growth patterns similar to those of their breast-fed counterparts. Lowering the $18: 2 n-6 / 18: 3 n-3$ ratio in infant formula from $10: 1$ to $5: 1$ had no effect, either positive or negative, from birth to 8 months of age $\mathrm{e}^{3}$. All of these trials were conducted in affluent countries on infants who, regardless of diet, already had a near optimum growth rate. Furthermore, most formulas tested had $n-6 / n-3$ PUFA ratios close to those of breast milk fed to control groups. Under these conditions, the impact of PUFA on weight gain was probably limited or barely visible. In contrast to the reviews mentioned above,
Xiang and Zetterstrom ${ }^{4}$ (not cited by the reviewers) observed that concentrations of 20:4n-6 and 22:6n-3 in breast milk correlated positively with infant weight gains at the third month, and Jensen et al. ${ }^{5}$ found an adverse effect on infants fed formula with a low $18: 2 n-6 / 18: 3 n-3$ ratio of $4.8: 1$. In most developing countries, in which the socio-economic status of populations is precarious and the dietary habits in infants inadequate, infant growth rates are lower than the current National Center for Health Statistics (NCHS)/World Health Organization (WHO) reference. Growth failure is often associated with too low intakes of protein and energy, as well as of essential micronutrients (minerals and vitamins), but the role of dietary PUFA is not known. Tichelaar et al. ${ }^{6}$ suspected that unbalanced (i.e. high) dietary $n-6 / n-3$ PUFA ratios had aggravating effects on stunting and called for more research on the subject. Dietary PUFA (precursors and LC derivatives) in developing countries 
are provided to infants mainly with breast milk. Traditional complementary foods fed as gruels to infants are low in fat and EFA and do not contain pre-formed LCPUFA ${ }^{7}$.

Our previous surveys on the EFA status of 5-month-old infants living in suburban districts of Brazzaville (capital of The Congo) and Ouagadougou (capital of Burkina Faso) showed remarkable disparities between the two locations with regard to EFA and LCPUFA concentrations in breast milk ${ }^{8-10}$. Breast milk in Brazzaville contained nearly three times more $n-3$ PUFA than in Ouagadougou (2.4\% vs. $0.9 \%$ ) and conversely much less $n-6$ PUFA (14.9\% vs. 21.7\%). Differences were due to distinct dietary habits of the nursing mothers. Consequently, breast milk displayed high discrepancies in the $18: 2 n-6 / 18: 3 n-3$ ratio (12:1 in Brazzaville vs. 53:1 in Ouagadougou), as well as in the LCPUFA $n-6$ /LCPUFA $n-3$ ratio (1:1 in Brazzaville vs. $5: 1$ in Ouagadougou). Concomitantly, anthropometric measurements showed that, in Brazzaville, infants at 5 months of age were significantly heavier than in Ouagadougou. The aim of the current paper was therefore to evaluate, among other nutritional or non-nutritional factors, the implication of breast milk PUFA content on infant growth and particularly that of the $n-6 / n-3$ PUFA ratios.

\section{Materials and methods}

\section{Study population}

Surveys were conducted in two suburban districts, one in Brazzaville (capital of The Congo) and the other in Ouagadougou (capital of Burkina Faso). Selection of term infants and their mothers has been described in detail previously ${ }^{8,10}$. The number of infants enrolled in each cohort $(n \approx 100)$ was representative of the district population of 5-month-old infants. Information on socioeconomic status and education of the mothers, and on infant feeding practices, was recorded with the help of pre-tested questionnaires. Dietary habits of the mothers were established with the use of food-frequency questionnaires as detailed previously ${ }^{9,10}$.

Permission to conduct the studies was obtained from the Burkinabè and Congolese Ministries of Research and of Health but no specific ethical approval could be obtained because no ethical review committees existed in these countries. Parents were informed in their local language about the study and gave their oral consent.

\section{Anthropometry of mothers and infants}

All anthropometric measurements, interviews with mothers and milk samplings were conducted at the mothers' homes. Birth weight was recorded from the birth certificate. Infants were weighed unclothed on Seca baby scales to the nearest $10 \mathrm{~g}$. Body height was measured in the supine position to the nearest $\mathrm{mm}$ by two individuals using a wooden gauge with a fixed headboard and a movable footboard. Weight-for-age, weight-for-height and height-for-age $Z$-scores were calculated using Epi-Info version 6 software (Center for Disease Control, Atlanta, GA) and compared with the NCHS standards. Mothers were weighed to the nearest $200 \mathrm{~g}$ on electronic scales. Body height was measured to the nearest mm using a height gauge.

\section{Lipid and fatty acid concentrations of breast milk and complementary foods fed to infants}

Results presented here were adapted from already published data collected on the same subjects ${ }^{8,10}$.

\section{Statistical analysis}

This study attempted to test the hypothesis that breast milk fatty acids (FA) (PUFA in particular) might affect infant growth. Student's $t$-test was applied for comparing quantitative variables (i.e. anthropometry of mothers and infants from Brazzaville with their counterparts in Ouagadougou, total fat and FA composition of breast milk). These data are presented as means \pm standard deviation. The chi-square test was used to compare qualitative variables presented as percentages (maternal education and socio-economic status, feeding practices and health status of infants).

General linear models were conducted to investigate the effect of breast milk FA on infant growth. All recorded variables that might have an impact on infant growth were considered as independent covariates for these models. These included gender, maternal anthropometry, education and socio-economic status, infant feeding practices, and health status. Variables that were significantly associated with the dependent variable (i.e. growth) were adjusted for in these analyses. Because the relationship between growth and milk PUFA in Brazzaville differed from that in Ouagadougou, the two settings were treated separately.

Socio-economic and education data of mothers, as well as anthropometry of mothers and infants, were processed using Epi-Info 6 software. Other statistical analyses were carried out with SAS for Windows software, version 8.2 (SAS Institute, Inc., Cary, NC). A significance level of $P<0.05$ was taken, unless mentioned otherwise.

\section{Results}

\section{Antbropometry and socio-economic status of motbers}

Mean age, height and body mass index (BMI) of the mothers in the two locations were similar (Table 1). Maternal education level and socio-economic status were higher in Brazzaville than in Ouagadougou. However, unemployment was high in both groups.

\section{Infant feeding practices}

There were no exclusively breast-fed infants in either group (Table 2). At 5 months of age 98\% of Congolese 
Table 1 Anthropometric characteristics, education and socioeconomic status of mothers

\begin{tabular}{lccc}
\hline & Brazzaville & Ouagadougou & $P$-value \\
\hline$n$ & 102 & 101 & \\
Maternal age (years) & $27.0 \pm 6.8$ & $28.6 \pm 7.0$ & $\mathrm{NS}$ \\
Height (m)* & $1.61 \pm 0.06$ & $1.62 \pm 0.05$ & $\mathrm{NS}$ \\
BMl (kg m$\left.{ }^{-2}\right)^{*}$ & $22.3 \pm 4.5$ & $23.0 \pm 4.0$ & $\mathrm{NS}$ \\
Maternal education (\%) & & & \\
$\quad$ None & 3.9 & 57.4 & \\
$\quad$ Primary school level & 14.7 & 23.8 & $<0.0001$ \\
$\quad$ Secondary school level & 77.5 & 17.8 & \\
$\quad$ Higher level & 3.9 & 1.0 & \\
Mother's occupation (\%) & & & \\
$\quad$ None & 51.0 & 64.4 & $\mathrm{NS}$ \\
Homes (\%) with & & & \\
$\quad$ No electricity & 62.8 & 78.2 & $<0.05$ \\
$\quad$ No refrigerator or freezer & 78.2 & 92.1 & $<0.01$ \\
$\quad$ No private water supply & 39.2 & 83.2 & $<0.0001$ \\
$\quad$ No private toilets & 60.8 & 97.0 & $<0.0001$ \\
$\quad$ Radio set & 72.6 & 78.2 & NS \\
$\quad$ TV set & 51.0 & 26.7 & $<0.001$ \\
\hline
\end{tabular}

$\mathrm{BMI}$ - body mass index; NS - not significant.

*Values given as mean \pm standard deviation.

Table 2 Feeding practices of infants (\%)

\begin{tabular}{|c|c|c|c|}
\hline \multirow[b]{2}{*}{$n$} & \multicolumn{2}{|c|}{ Brazzaville Ouagadougo } & $P$-value \\
\hline & 102 & 101 & \\
\hline Exclusively breast-feeding & 0 & 0 & NS \\
\hline Extra fluids* & 51.0 & 100 & $<0.0001$ \\
\hline Bottle-feeding & 13.7 & 13.9 & NS \\
\hline Predominantly breast-feeding $\dagger$ & 2.0 & 39.6 & $<0.0001$ \\
\hline Complementary feeding & 98.0 & 60.4 & $<0.0001$ \\
\hline
\end{tabular}

NS - not significant.

* Water and/or herb tea, fruit juices.

† Breast milk and extra fluids, no solid foods.

infants were already receiving complementary foods (CF; i.e. breast milk, plus other fluids eventually and solid foods), whereas in Ouagadougou 40\% of infants were still predominantly breast-fed (PBF; i.e. breast milk plus other fluids), while 60\% were CF. All Burkinabè infants had been given fluids other than milk since birth, but this was the case for only half of the infants in Brazzaville. Bottle-feeding was practised in only $14 \%$ of infants in the two groups. Age at first introduction of complementary foods (Table 3) was less than 3 months in Brazzaville, and 3-4 months in Ouagadougou. The number of gruel servings per day was between 2 and 3 in both groups, but actually there were more 3 servings per day in Ouagadougou.

\section{Antbropometry of infants}

All infants were born at term. The number of low-birthweight $(<2500 \mathrm{~g})$ infants, mean birth weight and length at 5 months of age were similar in both groups (Table 4). Infants in Ouagadougou were older by only 6 days. Their weight-for-age and weight-for-height $Z$-scores and weight gain $(\mathrm{g})$ were significantly lower than those of infants in Brazzaville. Ouagadougou infants were further divided
Table 3 Age at introduction of complementary feeding (CF) and number of gruel servings per day. Values given as $\%$

\begin{tabular}{lcc|c}
\hline & Brazzaville & Ouagadougou & $P$-value \\
\hline$n$ & 100 & 61 & \\
Age (months) & at introduction of CF & & \\
$<3$ & 41.0 & 0 & \\
$3-4$ & 53.0 & 47.5 & $<0.0001$ \\
$>4$ & 6.0 & 52.5 & \\
Number of gruel servings per day & & \\
1 & 10.0 & 8.2 & \\
2 & 61.0 & 39.3 & \\
3 & 27.0 & 50.8 & \\
4 & 2.0 & 1.6 & \\
\hline
\end{tabular}

into two subgroups based on their feeding practices (i.e. those still PBF and those already CF) and compared for their weight gain (Table 5). Their growth was similar.

\section{Lipid and PUFA concentrations in foods fed to infants}

Breast milk

Milk fat content was slightly lower in Brazzaville (Table 6). Concentrations of C8:0-C14:0 FA were very high, especially in Ouagadougou. Long-chain saturated (C15:0-C24:0) and monounsaturated FA concentrations did not differ from one group to another. The main differences lay in PUFA concentrations. Breast milk in Ouagadougou supplied approximately twice as much $n-6$ PUFA as that in Brazzaville, but conversely, it provided half as much $n-3$ PUFA. Consequently, 18:2n-6/18:3n-3 and LC $n-6 /$ LC $n-3$ ratios were respectively 4.3 and 4.5 times higher in Ouagadougou than in Brazzaville.

\section{Complementary foods (gruels)}

Corn flour in both settings, but also millet in Ouagadougou, were the staple flours used to prepare gruels at home (Table 7). A commercial infant formula (Cerelac) was intermittently fed to $11.5 \%$ of infants in Ouagadougou compared with 5\% in Brazzaville. Flours provided no LC $n-6$ or LC $n-3$ PUFA, but only the EFA precursors (linoleic and $\alpha$-linolenic acids). From this standpoint, millet flour (fermented or not) contained more 18:2n-6 and $18: 3 n-3$ than the others and had a balanced $18: 2 n-6 / 18: 3 n-3$ ratio. Corn flour displayed the highest 18:2n-6/18:3n-3 ratio.

\section{Relationship between milk fatty acids and infant growtb}

All the FA families (i.e. saturates, monounsaturates, $n-6$ and $n-3$ PUFA) were tested for their relationship with infant growth, but only in Brazzaville did the 18:2n-6/ $18: 3 n-3$ ratio have a significant effect. Figure 1 shows the distribution of the $18: 2 n-6 / 18: 3 n-3$ ratio values found in breast milk in the two settings and their relationship with 
Table 4 Anthropometry of infants at 5 months of age

\begin{tabular}{lccc}
\hline & Brazzaville & Ouagadougou & $P$-value \\
\hline$n$ & 102 & 101 & \\
Gender (ratio males/females) & $54 / 46$ & $56 / 44$ & $\mathrm{NS}$ \\
\% Low birth weights $(<2500 \mathrm{~g})$ & 10.9 & 7.1 & $\mathrm{NS}$ \\
Birth weight $(\mathrm{g})^{\star}$ & $3078 \pm 433$ & $3065 \pm 410$ & $\mathrm{NS}$ \\
Age (months) & $4.9 \pm 0.3$ & $5.1 \pm 0.2$ & $<0.0001$ \\
Length $(\mathrm{cm})^{*}$ & $63.3 \pm 2.5$ & $63.7 \pm 2.6$ & $\mathrm{NS}$ \\
Weight-for-age Z-score & -0.35 & -0.94 & $<0.0001$ \\
Weight-for-height Z-score & 0.07 & -0.68 & $<0.0001$ \\
Height-for-age Z-score & -0.60 & -0.63 & $\mathrm{NS}$ \\
Weight gain (g month $\left.^{-1}\right)^{*}$ & $720.4 \pm 175.9$ & $614.4 \pm 168.0$ & $<0.0001$ \\
\hline
\end{tabular}

NS - not significant.

*Values given as mean \pm standard deviation.

Table 5 Compared anthropometry of predominantly breast-fed (PBF) and complementary fed (CF) infants in Ouagadougou. Values given as mean \pm standard deviation

\begin{tabular}{lccc}
\hline & PBF & CF & $P$-value \\
\hline$n$ & 40 & 61 & \\
Birth weight (g) & $3014 \pm 368$ & $3100 \pm 435$ & NS \\
Age (months) & $5.1 \pm 0.2$ & $5.1 \pm 0.2$ & NS \\
Weight gain $\left({\text { m } \text { month }^{-1} \text { ) }}^{2}\right.$ & $602.7 \pm 180.0$ & $631.7 \pm 149.1$ & NS
\end{tabular}

NS - not significant.

infant weight gain. It clearly appeared that Brazzaville and Ouagadougou constituted two distinct populations. Indeed, in Brazzaville, 84 out of 100 samples of milk had a 18:2n-6/18:3n-3 ratio within recommended values (i.e. $5: 1<18: 2 n-6 / 18: 3 n-3<15: 1$ ) versus only one out of 99 samples in Ouagadougou. Also in Brazzaville but not in Ouagadougou, a negative linear relationship $(P=0.014)$ was observed between the $18: 2 n-6 / 18: 3 n-3$ ratio and infant weight gain. Each infant population was further divided into three subgroups according to the value of the $18: 2 n-6 / 18: 3 n-3$ ratio. In Brazzaville, two groups of infants (BR1 and BR2) corresponded to those fed milk having balanced ratios (i.e. BR1 $=5: 1<18: \quad 2 n-6 / 18: 3 n-3<11: 1, \quad$ and $\mathrm{BR} 2=11: 1<18: 2 n-6 / 18: 3 n-3<15: 1)$ and the third one (UBR) included those fed an unbalanced ratio (i.e. $\mathrm{UBR}=18: 2 n-6 / 18: 3 n-3>15: 1$ ). In Ouagadougou, since all milks except one showed unbalanced ratios, no such grouping was possible so the infant population was divided in tertiles. Table 8 shows that in Brazzaville the relationship between the $18: 2 n-6 / 18: 3 n-3$ ratio and growth indeed was non-linear. In fact, weight gain decreased when the $18: 2 n-6 / 18: 3 n-3$ ratio became unbalanced $(>15: 1)$. Independent confounding factors that had a significant effect on weight gain were total fat in milk, infant sex and health status (good vs. poor as estimated by the mothers when questioned), and maternal socio-economic status. Effect of the 18:2n-6/18:3n-3 ratio adjusted with these covariates was even more significant $(P=0.0011)$. Applying the same model in Ouagadougou did not show such a relation (Table 8).
Table 6 Milk fat and fatty acid concentrations $\left(\mathrm{gl}^{-1}\right)$ at sampling*. Values given as mean \pm standard deviation

\begin{tabular}{lccc}
\hline & Brazzaville & Ouagadougou & $P$-value \\
\hline Fat & $28.59 \pm 11.34$ & $33.42 \pm 9.84$ & $<0.01$ \\
Saturates & & & \\
$\quad$ C8:0-C14:0 & $7.17 \pm 3.19$ & $8.86 \pm 3.44$ & $<0.001$ \\
$\quad$ C15:0-C24:0 & $7.73 \pm 3.26$ & $8.27 \pm 2.69$ & $\mathrm{NS}$ \\
Monounsaturates & $8.36 \pm 3.81$ & $8.22 \pm 2.88$ & $\mathrm{NS}$ \\
PUFA & & & \\
18:2n-6 & $3.98 \pm 2.15$ & $6.73 \pm 2.83$ & $<0.0001$ \\
20:4n-6 & $0.12 \pm 0.06$ & $0.21 \pm 0.08$ & $<0.0001$ \\
LC $n-6$ PUFA & $0.34 \pm 0.16$ & $0.63 \pm 0.21$ & $<0.0001$ \\
18:3n-3 & $0.34 \pm 0.21$ & $0.15 \pm 0.08$ & $<0.0001$ \\
22:6n-3 & $0.15 \pm 0.07$ & $0.08 \pm 0.05$ & $<0.0001$ \\
LC $n-3$ PUFA & $0.33 \pm 0.16$ & $0.15 \pm 0.09$ & $<0.0001$ \\
Ratios & & & \\
18:2n-6/18:3n-3 & $12.3 \pm 3.3$ & $52.6 \pm 27.6$ & $<0.0001$ \\
LC $n-6 /$ LC $n-3$ & $1.1 \pm 0.4$ & $4.9 \pm 1.9$ & $<0.0001$ \\
\hline
\end{tabular}

NS - not significant; LC - long-chain; PUFA - polyunsaturated fatty acids. ${ }^{*}$ Adapted from Rocquelin et al. ${ }^{8,10}$.

\section{Discussion}

Our data regarding infant anthropometry and feeding practices coincided with those established previously in the same two countries ${ }^{11,12}$. Our study showed that, in Brazzaville, infant weight gain at 5 months of age was highest when the $18: 2 n-6 / 18: 3 n-3$ ratio in breast milk was between 5:1 and 15:1, which is the recommended range of values for optimum infant development ${ }^{13,14}$.

Table 7 Fat and polyunsaturated fatty acid concentrations in flours fed as gruels to infants in Brazzaville and Ouagadougou

\begin{tabular}{|c|c|c|c|c|}
\hline & $\begin{array}{c}\text { Fat } \\
(\mathrm{g} / 100 \mathrm{~g})\end{array}$ & $\begin{array}{l}18: 2 n-6 \\
(\mathrm{mg} / 100 \mathrm{~g})\end{array}$ & $\begin{array}{l}18: 3 n-3 \\
(\mathrm{mg} / 100 \mathrm{~g})\end{array}$ & $18: 2 n-6 / 18: 3 n-3$ \\
\hline \multicolumn{5}{|l|}{ Brazzaville } \\
\hline Corn flour & 2.31 & 1115 & 23 & 55.5 \\
\hline Cerelac* & 6.70 & 1080 & 73 & 14.8 \\
\hline \multicolumn{5}{|c|}{ Ouagadougou } \\
\hline Corn flour & 1.33 & 601 & 12 & 50.0 \\
\hline Millet & 5.14 & 2542 & 185 & 13.7 \\
\hline $\begin{array}{l}\text { Fermented } \\
\text { millet }\end{array}$ & 4.02 & 1973 & 125 & 15.8 \\
\hline Cerelac* & 3.73 & 811 & 29 & 28.0 \\
\hline
\end{tabular}

${ }^{*}$ Commercial infant formula. 


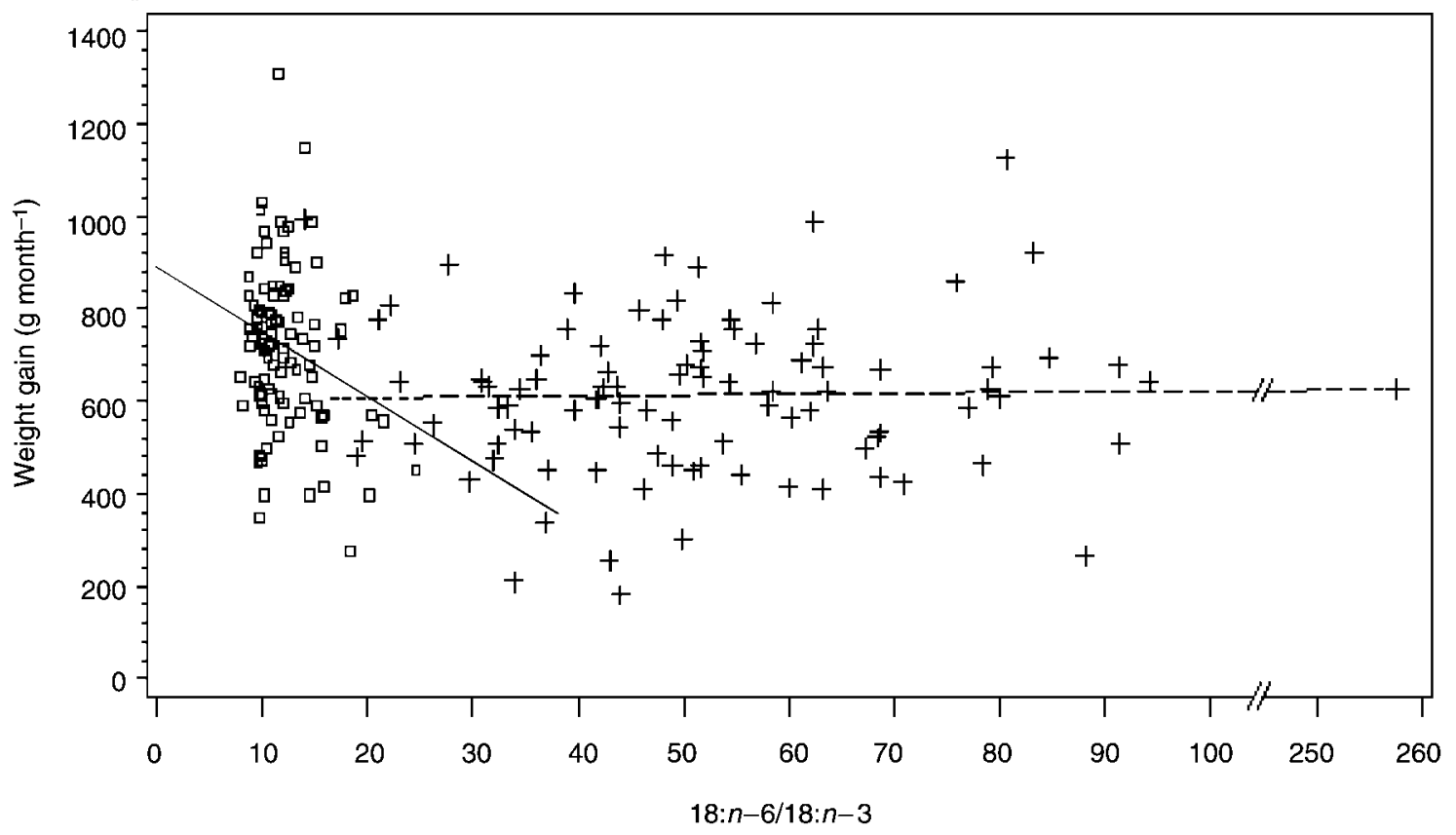

Fig. 1 Relationship between infant weight gain and 18:2n-6/18:3n-3 ratio in Brazzaville $(\square)$ and Ouagadougou (+). Brazzaville: $y$ (weight gain) $=889.84-14.021 x(18: 2 n-6 / 18: 3 n-3$ ratio). Ouagadougou: $y$ (weight gain) $=602.94+0.2001 x(18: 2 n-6 / 18: 3 n-3$ ratio $)$

At higher values (i.e. from 15:1 up to 24:1) there was a decline in weight gain which, however, did not intensify further beyond these values such as those encountered in Ouagadougou. To our knowledge, this is the first time that an observational study has demonstrated an effect of milk 18:2n-6/18:3n -3 ratio on infant weight growth. Our findings confirm Tichelaar et al.'s assumption ${ }^{6}$ but are in contrast with those of Jensen et al. ${ }^{5}$, who found that infants fed formula with a high 18:2n-6/18:3n-3 ratio (i.e. 44:1, close to that found in Ouagadougou breast milk) gained more weight at 4 months of age than those fed formula with a low 18:2n-6/18:3n-3 ratio of 4.8:1. However, it is hard to compare Jensen et al.'s findings with ours, since their tested infant formulas did not contain pre-formed LCPUFA and also differed from the current breast milks in other FA contents (saturates and monounsaturates).
In Brazzaville as well in Ouagadougou, dietary habits of mothers were consistent all year round, as reported by the food-frequency questionnaires, and it can thus be assumed that milk PUFA composition remained fairly constant throughout the 5 months of lactation. Indeed, numerous studies carried out in Western countries ${ }^{15-19}$ have shown slight variations in individual PUFA of breast milk, but no significant changes in the proportions of total $n-6$ and $n-3$ PUFA over several months of lactation in women fed diets that were clearly more diversified than in our populations. Therefore, in both settings the infants were probably breast-fed milk with unchanged $n-6 / n-3$ PUFA ratios during the 5-month lactating period. Nonetheless, the reason why infants in Ouagadougou gained less weight than their counterparts in Brazzaville still remains to be elucidated. It is not due to the qualitative variables tested for their impact on infant

Table 8 General linear model: weight gain $\left(\mathrm{g} \mathrm{month}^{-1}\right)$ of 5-month-old infants in Brazzaville $(n=98)$ and Ouagadougou $(n=98)$

\begin{tabular}{|c|c|c|c|c|c|c|}
\hline \multicolumn{2}{|l|}{ Setting } & $F$ & $P$-value & \multicolumn{3}{|c|}{ Mean } \\
\hline Brazzaville & $\begin{array}{l}\text { Divided into three classes } \\
\text { 18:2n-6/18:3n-3 effect } \\
18: 2 n-6 / 18: 3 n-3 \text { adjusted effect* }\end{array}$ & $\begin{array}{l}6.27 \\
7.39\end{array}$ & $\begin{array}{l}0.0027 \\
0.0011\end{array}$ & $\begin{array}{c}\text { BR1 }(n=47) \\
714.1^{\mathrm{a}} \\
\quad 679.8^{\mathrm{a}}\end{array}$ & $\begin{array}{c}\text { BR2 }(n=36) \\
777.1^{\mathrm{a}} \\
720.4^{\mathrm{a}}\end{array}$ & $\begin{array}{c}\operatorname{UBR}(n=15) \\
595.1^{\mathrm{b}} \\
544.9^{\mathrm{b}}\end{array}$ \\
\hline Ouagadougou & $\begin{array}{l}\text { Divided into tertiles } \\
\text { 18:2n-6/18:3n-3 effect } \\
\text { 18:2n-6/18:3n-3 adjusted effect } †\end{array}$ & $\begin{array}{l}0.26 \\
1.70\end{array}$ & $\begin{array}{l}0.77 \\
0.54\end{array}$ & $\begin{array}{l}\text { Tertile } 1(n=32) \\
602.4^{\mathrm{a}} \\
592.7^{\mathrm{a}}\end{array}$ & $\begin{array}{c}\text { Tertile } 2(n=34) \\
607.5^{\mathrm{a}} \\
572.2^{\mathrm{a}}\end{array}$ & $\begin{array}{c}\text { Tertile } 3(n=32) \\
631.0^{\mathrm{a}} \\
645.1^{\mathrm{a}}\end{array}$ \\
\hline
\end{tabular}

a,b Means with no common letter are significantly different at the 0.05 level.

${ }^{*}$ Adjusted for total lipid content (divided into tertiles), gender, infant health and maternal socio-economic status.

† Adjusted for total lipid content (divided into tertiles), gender, infant health, maternal body mass index, education and socio-economic status. 
growth (i.e. gender, infant health status, maternal BMI, education and socio-economic status) since none of them had a significant effect.

Growth-promoting nutrients other than total fat and PUFA supplied by breast milk and complementary foods were not measured in this study but their impact on weight gain is unlikely. In fact, diets consumed by mothers in Ouagadougou were very similar in nature and consistent all year round and thus they probably did not induce significant differences in nutrient contents in breast milk. It is mainly when the mothers' nutritional status differs greatly (e.g. in affluent countries vs. developing countries) that changes in the nutrient composition of breast milk and consequently in infant growth rates are observed ${ }^{20,21}$. It is also unlikely that the decline in weight growth was due to complementary foods since CF infants had the same weight gains as their PBF counterparts. One explanation could be the noticeable daily intake by infants of fluids other than milk, which can reduce milk consumption and consequently its content of growth-promoting nutrients. However, to what extent high intake of extra fluids has a negative impact on infant growth by diminishing breast milk intake is not clearly established ${ }^{22}$.

In conclusion, our data strongly support the beneficial effect of a balanced 18:2n-6/18:3n-3 ratio in breast milk on infant weight gain during postnatal life. The fact that it was established in field studies reinforces the argument already advanced by the United Nations Children's Fund ${ }^{23}$ that EFA, as well as other vital micronutrients, can play a significant role in preventing infant growth failure in developing countries. It also confirms the need to improve mothers' diets if they are low or unbalanced in EFA and/or LCPUFA derivatives, so as to restore balanced $n-6 / n-3$ PUFA ratios in breast milk. In the case of Ouagadougou, and also in rural areas of Burkina Faso (results to be published), one public health measure would be to increase the maternal intake of local foods containing $n-3$ PUFA (e.g. fish and green leafy vegetables). This will necessitate local authorities to encourage increased production of vegetables and fish, alongside nutrition education strategies targeting mothers.

In addition, it is vital that EFA are recognised as micronutrients. This would help in better understanding the causes of malnutrition and identifying appropriate interventions in developing countries.

\section{Acknowledgements}

Our deepest thanks go to the mothers and their infants for their warm welcome, their kindness, and their availability throughout these surveys. We are also indebted to the Congolese and Burkinabè Ministries of Research and of Health, who authorised us to conduct the surveys in Brazzaville and Ouagadougou. The work was supported in part by the Institut National de la Recherche Agronomique.

\section{References}

1 Gibson RA, Chen W, Makrides M. Randomized trials with polyunsaturated fatty acid interventions in preterm and term infants: functional and clinical outcomes. Lipids 2001; 36: 873-83.

2 Lapillonne A, Carlson SE. Polyunsaturated fatty acids and infant growth. Lipids 2001; 36: 901-11.

3 Makrides M, Neumann MA, Jeffrey B, Lien EL, Gibson RA A randomized trial of different ratios of linoleic to $\alpha$-linolenic acid in the diet of term infants: effect on visual function and growth. Am. J. Clin. Nutr. 2000; 71: 120-9.

4 Xiang M, Zetterstrom R. Relation between polyunsaturated fatty acids and growth. Acta Paediatr. 1999; 88: 78-82.

5 Jensen CL, Prager TC, Fraley JK, Chen H, Anderson RE, Heird WC. Effect of dietary linoleic/alpha-linolenic acid ratio on growth and visual function of term infants. J. Pediatr. 1997; 131: 200-9.

6 Tichelaar HY, Dhansay MA, Smuts CM, Faber M, Van Jaarsveld PJ, Oelofse A, et al. Fatty acid and nutritional status in children under two years of age from a low socio-economic community. S. Afr. Food Sci. Nutr. 1995; 7: 109-14.

7 Beare-Rogers J, Ghafoorunissa, Korver O, Rocquelin G, Sundram K, Uauy R. Dietary fat in developing countries. Food Nutr. Bull. 1998; 18: 251-66.

8 Rocquelin G, Tapsoba S, Dop MC, Mbemba F, Traissac P, Martin-Prével Y. Lipid content and essential fatty acid (EFA) composition of mature Congolese breast milk are influenced by mothers' nutritional status: impact on infants' EFA supply. Eur. J. Clin. Nutr. 1998; 52: 164-71.

9 Rocquelin G, Tapsoba S, Mbemba F, Gallon G, Picq C. Lipid content and fatty acid composition in foods commonly consumed by nursing Congolese women: incidences on their essential fatty acid intakes and breast milk fatty acids. Int. J. Food Sci. Nutr. 1998; 49: 343-52.

10 Rocquelin G, Kiffer J, Tapsoba S, Bouda C. High proportions of $n-6$ polyunsaturated fatty acids in mature milk of mothers in Ouagadougou, Burkina Faso. Acta Paediatr. 2001; 90: 450-52.

11 Cornu A, Trèche S, Massamba JP, Massamba J, Delpeuch F. Alimentation de sevrage et interventions nutritionnelles au Congo. Cahiers Santé 1993; 3: 168-71.

12 DHS Demographic and Health Surveys, Burkina Faso 1998-1999. Ouagadougou, Burkina Faso/Calverton, MD: INSD/Macro International Inc., 2000.

13 Food and Agriculture Organization (FAO). Fats and Oils in Human Nutrition. Report of a Joint Expert Consultation. Food and Nutrition Paper No. 57. Rome: FAO, 1994.

14 Buttriss J. $n-3$ Fatty Acids and Health. Briefing Paper London: British Nutrition Foundation, 1999; 1-44.

15 Guesnet P, Antoine JM, Rochette de Lempdes JB, Galent A, Durand G. Polyunsaturated fatty acid composition of human milk in France: changes during the course of lactation and regional differences. Eur. J. Clin. Nutr. 1993; 47: $700-10$.

16 Jensen GJ. Lipids in human milk. Lipids 1999; 34: 1243-71.

17 Koletzko B, Rodriguez-Palmero M. Polyunsaturated fatty acids in human milk and their role in early infant development. J. Mamm. Gland Biol. Neoplasia 1999; 4 269-84.

18 Makrides M, Simmer K, Neumann M, Gibson R. Changes in the polyunsaturated fatty acids of breast milk from mothers of full-term infants over $30 \mathrm{wk}$ of lactation. Am.J. Clin. Nutr. 1995; 61: 1231-3.

19 Marangoni F, Agostoni C, Lammardo AM, Giovannini M, Galli C, Riva E. Polyunsaturated fatty acid concentration in human hindmilk are stable throughout 12-months of lactation and provide a sustained intake to the infant during exclusive breastfeeding: an Italian study. Br. J. Nutr. 2000; 84: 103-9. 
20 World Health Organization (WHO). Complementary Feeding of Young Children in Developing Countries: A Review of Current Scientific Knowledge. WHO/NUT/98.1. Geneva: WHO, 1998; 1-228.

21 World Health Organization (WHO). The Quantity and Quality of Breast Milk. Report on the WHO Collaborative Study on Breast-feeding. Geneva: WHO, 1985.
22 Sachdev HPS, Krishna J, Puri RK, Satyanarayana L, Kumar S. Water supplementation in exclusively breastfed infants during summer in the tropics. Lancet 1991; 337: 929-33.

23 United Nations Children's Fund. What is malnutrition? In: Bellamy $\mathrm{C}$, ed. The State of the World's Children 1998. Focus on Nutrition. New York: Oxford University Press, 1998; 14. 